\title{
Exposure of neonatal rats to maternal cafeteria feeding during suckling alters hepatic gene expression and DNA methylation in the insulin signalling pathway
}

\author{
Zoe C. Daniel • Asli Akyol • Sarah McMullen • \\ Simon C. Langley-Evans
}

Received: 1 October 2013/Accepted: 10 November 2013/Published online: 20 December 2013

(C) Springer-Verlag Berlin Heidelberg 2013

\begin{abstract}
Nutrition in early life is a determinant of lifelong physiological and metabolic function. Diseases that are associated with ageing may, therefore, have their antecedents in maternal nutrition during pregnancy and lactation. Rat mothers were fed either a standard laboratory chow diet $(\mathrm{C})$ or a cafeteria diet $(\mathrm{O})$ based upon a varied panel of highly palatable human foods, during lactation. Their offspring were then weaned onto chow or cafeteria diet giving four groups of animals $(\mathrm{CC}, \mathrm{CO}, \mathrm{OC}, \mathrm{OO}$ $n=9-10$ ). Livers were harvested 10 weeks post-weaning for assessment of gene and protein expression, and DNA methylation. Cafeteria feeding post-weaning impaired glucose tolerance and was associated with sex-specific altered mRNA expression of peroxisome proliferator activated receptor gamma and components of the insulin signalling pathway (Irs2, Akt1 and $\operatorname{IrB}$ ). Exposure to the cafeteria diet during the suckling period modified the later response to the dietary challenge. Post-weaning cafeteria feeding only down-regulated $\operatorname{Ir} B$ when associated with cafeteria feeding during suckling (group OO, interaction of diet in weaning and lactation $P=0.041$ ). Responses to cafeteria diet during both phases of the experiment varied between males and females. Global DNA methylation was altered in the liver following cafeteria feeding in the postweaning period, in males but not females. Methylation of the $\operatorname{IrB}$ promoter was increased in group $\mathrm{OC}$, but not $\mathrm{OO}$
\end{abstract}

Z. C. Daniel · S. McMullen · S. C. Langley-Evans ( $₫)$ School of Biosciences, University of Nottingham, Sutton Bonington Campus, Loughborough LE12 5RD, UK e-mail: Simon.Langley-Evans@Nottingham.ac.uk

\section{Present Address:}

A. Akyol

Department of Nutrition and Dietetics, Hacettepe University, Ankara, Turkey
$(P=0.036)$. The findings of this study add to a growing evidence base that suggests tissue function across the lifespan a product of cumulative modifications to the epigenome and transcriptome, which may be both tissue and sex-specific.

Keywords Programming · Epigenetics · Insulin signalling $\cdot$ Cafeteria diet

\section{Introduction}

The concept of the developmental origins of health and disease founded on the observation that low birthweight and other sequelae of maternal undernutrition are associated with cardiovascular disease and type- 2 diabetes, is strongly supported by animal experiments (McMullen and Langley-Evans 2010). Variation in the quality or quantity of nutrient provision during pregnancy has a strong programming effect upon long-term health and well-being in the offspring of rodents, pigs, sheep and non-human primates (McMullen and Langley-Evans 2010).

Much of the work to date that has investigated the impact of maternal nutrition as a programming factor that determines physiological and metabolic function has focused upon maternal undernutrition. Food restriction (Vickers et al. 2003), protein restriction (Langley and Jackson 1994) and iron deficiency (Gambling et al. 2003) in rodent pregnancy all elicit similar phenotypes in the resulting offspring, including cardiovascular dysfunction (Yates et al. 2008; Torrens et al. 2009) impaired glucose homoeostasis (Fernandez-Twinn et al. 2005) and renal impairments (Langley-Evans et al. 1999). A smaller body of work has shown that maternal over-feeding, generally with high-fat diets, has similar programming effects in rats 
and mice (Samuelsson et al. 2008; Shankar et al. 2008). Work in our laboratory has demonstrated that feeding a cafeteria diet (a varying menu of highly palatable human foods) can impact upon metabolic function, with changes in glucose homoeostasis as determined by intraperitoneal glucose tolerance test (Akyol et al. 2012). This work established that foetal life is not the only period of sensitivity to the maternal diet. Feeding a cafeteria diet during lactation in the rat also altered responses to a glucose load and had powerful effects upon feeding and other behaviours (Wright et al. 2011a, b).

The most favoured explanation for associations between early dietary exposures and later physiological and metabolic function is that early diet impacts upon epigenetic marks and hence gene expression (Szyf 2009; Lillycrop and Burdge 2011). There is good evidence from animal models of undernutrition during foetal life that maternal diet can alter the epigenome, particularly DNA methylation, and this may establish changes in gene expression that permanently modify tissue structure or reset the responses to dietary and age-related challenges that occur later in life (Sinclair et al. 2007; Lillycrop et al. 2007; Bogdarina et al. 2010). Exposure to high-fat diets has been shown to alter DNA methylation and histone marks in rodents, non-human primates and primates, with the brain being particularly sensitive to dietary influences (Seki et al. 2012; Carlin et al. 2013; Langie et al. 2013; Jacobsen et al. 2012). The theory that epigenetic marks are solely vulnerable to nutritional programming in foetal life is now discounted as the epigenome responds to dietary cues at all life stages.

Whilst there is strong evidence of altered DNA methylation patterns across the whole genome in response to variation in maternal nutrition during pregnancy, it is not clear how wide the "window" for epigenetic programming in response to nutrition may be. Certainly, there is some evidence that a degree of plasticity remains into the pubertal growth phase in rats, as epigenetic marks on the peroxisome proliferator activated receptor alpha promoter respond to the folate content of the diet during this period (Burdge et al. 2009). With a long period of sensitivity to diet, it is of interest to determine whether the state of the epigenome following one set of dietary stimuli, for example in foetal life, can influence the response of the epigenome to a stimulus at a later stage.

The present study utilised tissue from the study previously reported by Akyol et al. (2012), as a preliminary investigation to establish the possible mechanistic basis of programming by maternal over-feeding in the lactation period. Specifically, we investigated the hypothesis that the observed metabolic phenotype is linked to cafeteria dietinduced changes in the insulin signalling pathway that are not just responses to current diet. The study also aimed to establish whether the epigenome is sensitive to maternal over-feeding during lactation or post-weaning.

\section{Materials and methods}

Experimental protocol and sample preparation

This paper describes a study which utilised a subset of tissue harvested from rats aged 3 months that had been subject to either maternal cafeteria diet feeding or a standard commercial chow diet during suckling. The full experiment which generated the tissue has been previously published (Akyol et al. 2012). The protocol is described briefly below.

The animal experiments were performed under licence from the Home Office in accordance with the 1986 Animals (Scientific Procedures) Act. Virgin female Wistar rats (aged 3 weeks) were fed standard laboratory chow diet (Harlan UK) from weaning until mating at age 10 weeks. On giving birth, all of the resulting litters were culled to a maximum of 8 pups ( 4 males and 4 females where possible, randomly selected) and were randomly allocated to be fed either a control chow diet alone ( $n=11$, chow control; C) or a control chow diet alongside an obesogenic random selection of highly energetic and palatable human foods ( $n=12$, cafeteria diet; O), as previously described by Akyol et al. (2009, 2012). All litters were weaned at 3 weeks of age and then half of the offspring from each litter were weaned onto the standard chow diet, and the remaining weanlings were allocated to receive chow and cafeteria diet. There were four groups of animals considered in this study: control in both lactation and post-weaning (CC); control in lactation, cafeteria post-weaning $(\mathrm{CO})$; cafeteria during lactation, control post-weaning (OC) and cafeteria diet in both lactation and post-weaning (OO).

At the age of 13 weeks, all offspring were subject to an intraperitoneal glucose tolerance test, following an 18-h fast, and were then culled (Akyol et al. 2012). Liver was rapidly dissected and snap-frozen in liquid nitrogen before storage at $-80{ }^{\circ} \mathrm{C}$. RNA was prepared from frozen tissue using Qiagen AllPrep kits according to the manufacturers instructions. DNA was extracted using Qiagen DNeasy kits. Protein extractions were performed by homogenising ground sample with 5 volumes of extraction buffer $(150 \mathrm{mM} \mathrm{NaCl}, 50 \mathrm{mM}$ HEPES, $2.5 \mathrm{mM}$ EDTA, $10 \%$ glycerol, $1 \%$ Triton, $1 \mathrm{mM} \mathrm{Na} \mathrm{VO}_{4}, 10 \mathrm{mM} \mathrm{NaF}$ ). After addition of 2 volumes SDS mix (glycerol, $1 \mathrm{M}$ Tris $/ \mathrm{HCl}$, $10 \%$ SDS, $0.154 \mathrm{~g} / \mathrm{ml}$ dithiothreitol 2:1.25:4:1 v:v:v:v), the samples were centrifuged at $13,000 \mathrm{rpm}$ for $10 \mathrm{~min}$ at $4{ }^{\circ} \mathrm{C}$. Protein content of supernatant was determined using the method of Lowry et al. (1951). Protein, DNA and RNA 
were all prepared from the same samples, with only one liver per litter selected for this study.

\section{Quantitative real-time PCR}

The transcription of a number of target genes was determined by quantitative real-time PCR. The targets included the insulin receptor $(\operatorname{IrB})$ and the glucose transporter Glut2 (Kahn 1997) as markers of the insulin signalling pathway (insulin receptor substrate 2; Irs 2 and the alpha serine/ threonine-protein kinase; Aktl had been previously measured in the same tissues, Akyol et al. 2012). The expression of peroxisome proliferator activated receptor alpha (PPARa) was determined as this transcription factor regulates hepatic glucose metabolism (Viana Abranches et al. 2011). Peroxisome proliferator activated receptor gamma (PPARg) expression was also measured as the effects of PPARg on adipocytes increase insulin sensitivity and the production of cytokines that regulate glucose homoeostasis (Floyd and Stephens 2012). Expression of acetyl CoA carboxylase $1(A c c 1)$ and carnitine-palmitoyl transferase 1a (Cptla) was determined as these are downstream targets of PPARa (Menendez-Gutierrez et al. 2012).

RNA was reverse transcribed using Moloney murine leukaemia virus (MMLV) reverse transcriptase (Promega, UK). Real-time PCR primers were designed for PPARa, PPARg, Glut2, IrB, ACC1 and Cpt1a using Primer Express software (version 1.5; Applied Biosystems) from the RNA sequence and were purchased from Sigma (UK). The primer sequences were as follows: Rat PPAR $a$ Fwd: CCACGAAGC CTACCTGAAGAACT Rvr: ACAAAAGGCGGATTGTT GCT; Rat PPARg gamma Fwd: GAATACCAAAGTGCG ATCAAAGTAGA Rvr: GGCCATGAGGGAGTTTGAA G; Rat Glut2 Fwd: TCAGCCAGCCTGTGTATGCA Rvr: TCCACAAGCAGCACAGAGACA; Rat $\operatorname{IrB}$ Fwd: GGAT TATTGTCTCAAAGGGCTGAA Rvr: CGTCATACTCAC TCTGATTGTGCTT; Rat ACCl Fwd: CCATTGGTATTG GGGCTTAC Rvr: CCGACCAAGGACTTTGTTG; Rat Cptla Fwd: CATTACAAGGACATGGGCAAGTT Rvr:T GTCCTCCCTTCTCGGAAGA. Primers were ordered from MWG Biotech, (Germany). Primer sequences for the housekeeping gene (cyclophilin) are published elsewhere (Austin and Langley-Evans 2011). Real-time PCR was performed using a Lightcycler 480 PCR machine (Roche, UK) and SYBR green, as previously described (Swali et al. 2012). Expression of the genes of interest was normalised to the housekeeping gene, expression of which was unaltered in response to the dietary treatments.

A Cayman Chemicals DNA Methylation EIA kit was used to estimate crude global DNA methylation in the samples. This assay measures 5-methyl-2'-deoxy cytidine in DNA. Methylation-specific real-time PCR was performed for PPARa, PPARg and IrB using the SABiosciences
EpiTect Methyl II PCR Primer assay, following the manufacturers instructions.

Western blotting

Protein expression was determined using Western blot, as described previously (Ryan et al. 2012). Primary antibodies were PPARa (Cayman Chemicals), PPARg (Santa Cruz), Glut2 (Millipore) and insulin receptor beta (cell signalling). Expression was normalised against beta-actin (Sigma) as a housekeeper. For Glut2, IrB, PPARa and PPARg, the secondary antibody was anti-rabbit, and for beta-actin, it was anti-mouse (both from Amersham). Signal was quantified using ECL Select (Amersham) developed on Hyperfilm (Amersham).

Statistical analysis

All data are presented as mean \pm SEM. Data were analysed by three-way analysis of variance (SPSS 20) to examine the influence of offspring sex, maternal diet during lactation and offspring diet from weaning until 3 months of age. $P \leq 0.05$ was accepted as statistically significant.

\section{Results}

The original experiment which generated the tissues for this study (Akyol et al. 2012) evaluated the impact of cafeteria diet prior to and during pregnancy, in addition to considering the effects of the diet during lactation upon glucose homoeostasis in the offspring. As the current study used a subset of groups from the original study, the glucose tolerance data from those groups were reanalysed to focus on the interaction between maternal diet during lactation and post-weaning diet (Fig. 1). After adjustment for sex, there was a significant interaction of the diet in lactation and postweaning $(P=0.039)$. Compared to group $\mathrm{CO}$, glucose tolerance was significantly impaired by cafeteria feeding in both periods $(\mathrm{OO})$. Glucose tolerance was not significantly different to group $\mathrm{CC}$ in any of the groups, although group $\mathrm{CO}$ cleared an i.p. glucose load moderately faster.

Our previously published work suggested that exposure to cafeteria diet at key stages of life altered expression of two components of the insulin signalling pathway (Irs2 and Aktl, Akyol et al. 2012). Confining the analysis to just the four groups of rats in this study confirmed the sensitivity of these genes to cafeteria diet as Irs2 was strongly up-regulated by post-weaning cafeteria diet in females only (2.64-fold, $P<0.001$, Table 1). Aktl expression was up-regulated by both cafeteria diet in lactation and post-weaning, but again 


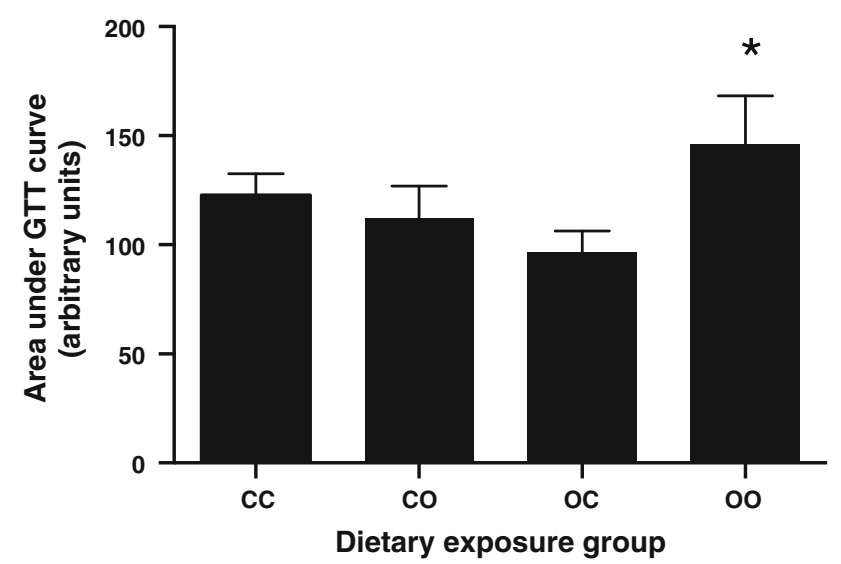

Fig. 1 Area under the curve from glucose tolerance test. Data are shown as mean \pm SEM for 9-10 observations per group. Data are shown for males and females combined (no significant effect of sex) and adjusted for sex. *indicates significantly different to OC $(P<0.05)$. Glucose tolerance area under the curve was influence by an interaction of lactation and post-weaning diet $(P=0.039)$. Reanalysis of data from Akyol et al. (2012)

Table 1 Impact of cafeteria diet during lactation and post-weaning on mRNA expression

\begin{tabular}{llllll}
\hline Gene & $\begin{array}{l}P \text { effect } \\
\text { of sex }\end{array}$ & $\begin{array}{l}\text { Lactation } \\
\text { fold } \\
\text { change } \\
\text { (OC and } \\
\text { OO vs. } \\
\text { CC and } \\
\text { CO) }\end{array}$ & $\begin{array}{l}P \text { effect } \\
\text { of } \\
\text { cafeteria } \\
\text { diet } \\
\text { during } \\
\text { lactation }\end{array}$ & $\begin{array}{l}\text { Post- } \\
\text { weaning } \\
\text { fold } \\
\text { change } \\
\text { (CO and } \\
\text { OO vs. CC } \\
\text { and OC) }\end{array}$ & $\begin{array}{l}P \text { effect } \\
\text { of } \\
\text { cafeteria } \\
\text { diet post- } \\
\text { weaning }\end{array}$ \\
\hline Irs 2 & 0.002 & -1.29 & NS & $1.63^{\S}$ & 0.043 \\
Akt1 & NS & $2.45^{*}$ & 0.008 & $-1.51^{*} €$ & NS \\
IrB & NS & $-1.04^{+}$ & NS & $-1.12^{+}$ & NS \\
Glut2 & NS & 1.06 & NS & 1.07 & NS \\
PPARa & 0.019 & -1.29 & 0.038 & 1.10 & NS \\
Cpt1a & 0.026 & 1.30 & 0.059 & $1.06^{\S}$ & NS \\
Acc1 & NS & 1.05 & NS & 1.17 & NS \\
PPARg & 0.002 & -1.04 & NS & $1.27^{\S}$ & NS \\
\hline
\end{tabular}

Data are shown as fold change ( - denotes down-regulation). $P$ values for lactation and post-weaning effects are univariate analyses. Interaction terms are not shown in this table, see legend Fig. 2, but are indicated by ${ }^{\S}$ (sex $\times$ post-weaning, $\left.P<0.05\right),{ }^{€}$ (lactation $\times$ postweaning, $P<0.05)$ and $*(\operatorname{sex} \times$ lactation $\mathrm{x}$ post-weaning, $P<0.05)$

only in females (interaction sex $\times$ post-weaning diet $\times$ lactation diet $P<0.05$, Table 1). The effects of cafeteria diet were not observed when the diet was fed in both the lactation and post-weaning periods; hence, expression was increased in groups OC (6.8-fold) and CO (2.9-fold), but not OO. Irs 2 expression was correlated with the area under the glucose tolerance curve $(r=0.450, P=0.006)$. Expression of two other components of the insulin signalling pathway indicated that
Glut2 expression was not influenced by cafeteria feeding (Figs. 2d, 3d), but $\operatorname{IrB}$ expression was influenced by sex, lactation diet and post-weaning diet (interaction $P=0.041$, Table 1; Figs. 2c, 3c). In females, it was only the animals suckled by cafeteria fed mothers that were sensitive to post-weaning cafeteria diet, but these OO females had reduced (20\% lower) expression of $\operatorname{Ir} B$ compared to CC.

The mRNA expression of PPARa differed markedly between male and female animals (lower in females) but was not significantly influenced by diet post-weaning. Exposure to cafeteria diet in lactation reduced PPARa expression $(P=0.038)$, as shown by the significant effect in males of group OO (Table 1; Figs. 2a, 3a). Similarly, PPARg was expressed at a lower level in females than males (25\% lower, Table 1; Figs. 2b, 3b), and specifically, in males of group $\mathrm{CO}$, expression was increased (1.37-fold) by feeding the cafeteria diet postweaning (sex x post-weaning diet interaction $P=0.05$ ). Given the significant effect of the lactation diet upon PPARa expression, the mRNA expression of the downstream targets Accl and Cptla was evaluated. Whilst Accl expression was unaffected by sex or diet at either stage of life (Table 1; Figs. 2e, 3e), Cptla expression (Table 1; Figs. 2f, 3f) was influenced by the interaction of sex and the post-weaning diet. In males of group OC, expression was significantly lower $(55 \%)$ than in all other groups, whilst in females of the same group, expression tended to be higher (significant compared to OO). Surprisingly, there was no correlation between expression of PPARa and either of the downstream targets, which may reflect the differential effects of the dietary exposures upon protein expression.

As shown in Table 2, global DNA methylation was significantly influenced by the post-weaning diet. In males but not females (interaction of sex $\times$ post-weaning diet $P=0018)$, post-weaning cafeteria diet significantly reduced global methylation. Methylation-specific PCR found no significant effects of cafeteria diet upon PPARa, where little methylation was detected in any of the groups (data not shown). There was some evidence that exposure to the cafeteria diet during lactation, followed by weaning onto chow, increased methylation of PPARg (group OC), but this was not statistically significant $(P=0.069$, Table 2). In contrast, there was a clear sensitivity of the $\operatorname{Ir} B$ promoter to effects of diet upon methylation. As with PPARg, the OC group exhibited greater methylation than in all other groups (interaction of lactation and postweaning $\operatorname{diet} P=0.036$ ).

Figure 4 shows the expression of PPARa, PPARg, Glut2 and $\operatorname{IrB}$ at the protein level. There were no significant effects of sex, maternal diet during lactation or offspring diet from weaning upon these proteins. 
Fig. 2 mRNA expression of insulin signalling pathwayrelated genes in male rat liver at 3 months of age. Data are shown as mean \pm SEM for 4-5 observations per group.

*indicates significantly different to $\mathrm{CC}(P<0.05),{ }^{\S}$ significantly different to $\mathrm{CO}(P<0.05)$, !significantly different to $\mathrm{OC}$ $(P<0.05)$. a PPARa expression was different in males and females $(P=0.019)$ and was influenced by exposure to cafeteria diet during lactation $(P=0.038)$. b PPARg expression was different in males and females $(P=0.002)$ and was influenced by the interaction of sex and cafeteria diet post-weaning $(P=0.050)$. c Glut2 expression was not influenced by sex or dietary exposures. d $\operatorname{IrB}$ expression was influenced by the interaction of sex, diet in lactation and diet post-weaning $(P=0.041)$. e $A c c 1$ expression was not influenced by sex or dietary exposures. f Cptla expression was influenced by sex $(P=0.026)$ and the interaction of sex and post-weaning diet $(P=0.023)$
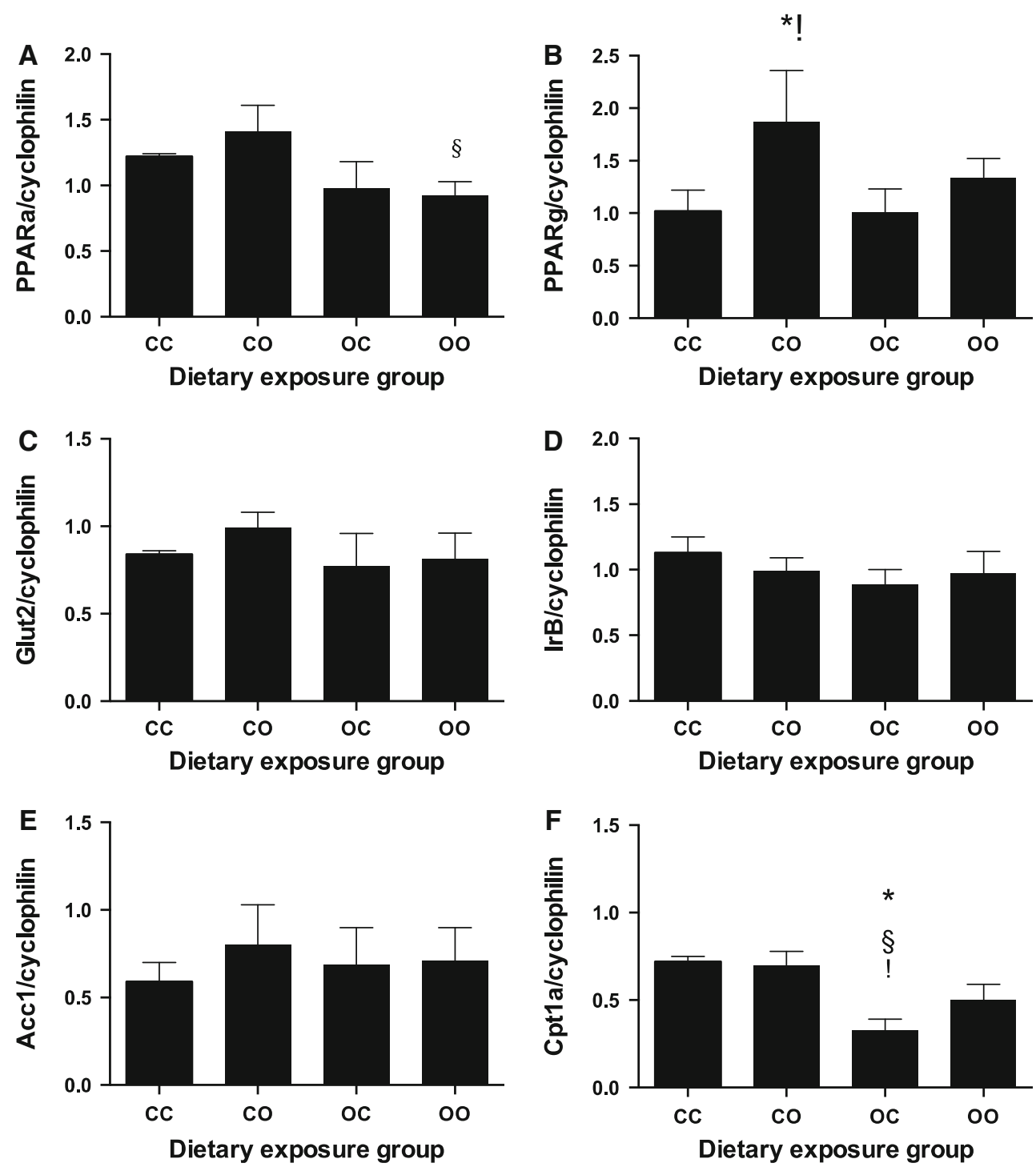

\section{Discussion}

Cafeteria feeding (Rothwell and Stock 1979) promotes obesity by overcoming the ability of rodents to regulate energy intake, as it provides a diet with high palatability and novelty. Our study replicated the original protocol and cafeteria feeding involved the addition of a constantly varied panel of high-sugar/high-fat foods to standard laboratory chow diet. This protocol was adopted as the literature (Buettner et al. 2007) demonstrates consistent evidence that a metabolic phenotype similar to that observed in the human can be induced. The combination of high fat with high sodium, sugars, saturated fat and cholesterol and low in fibre and micronutrients makes the protocol more closely aligned with dietary patterns observed in the humans than conventional purified high-fat diets used in rodent studies (Crozier et al. 2006; Kant 2004). It is considered the most effective tool for modelling the effects of "non-prudent" dietary patterns and dietinduced obesity in humans (Sampey et al. 2011).

The study examined two key hypotheses, and the data generated support the assertion that maternal cafeteria feeding during lactation programmes metabolic function through long-term alteration of expression of the insulin signalling and other metabolic pathways. We have also confirmed that the epigenome may be sensitive to this form of dietary challenge during the suckling phase in rodents. This corresponds with work demonstrating that high-fat diets can impact upon histone acetylation and DNA methylation in rodents and macaques (Aagaard-Tillery et al. 2008, Vucetic et al. 2010, 2011).

From a metabolic perspective, the animals most affected by the cafeteria diet were in the $\mathrm{OO}$ group. The slower clearance of a glucose load in this group is likely to be explained by their lower $\operatorname{Ir} B$ expression. Clearly, changes in expression of the insulin signalling pathway (IrB, Irs2 
Fig. 3 mRNA expression of insulin signalling pathwayrelated genes in female rat liver at 3 months of age. Data are shown as mean \pm SEM for 4-5 observations per group.

*indicates significantly different to $\mathrm{CC}(P<0.05),{ }^{\S}$ significantly different to $\mathrm{CO}(P<0.05)$, 'significantly different to $\mathrm{OC}$ $(P<0.05)$. For full legend see Fig. 2
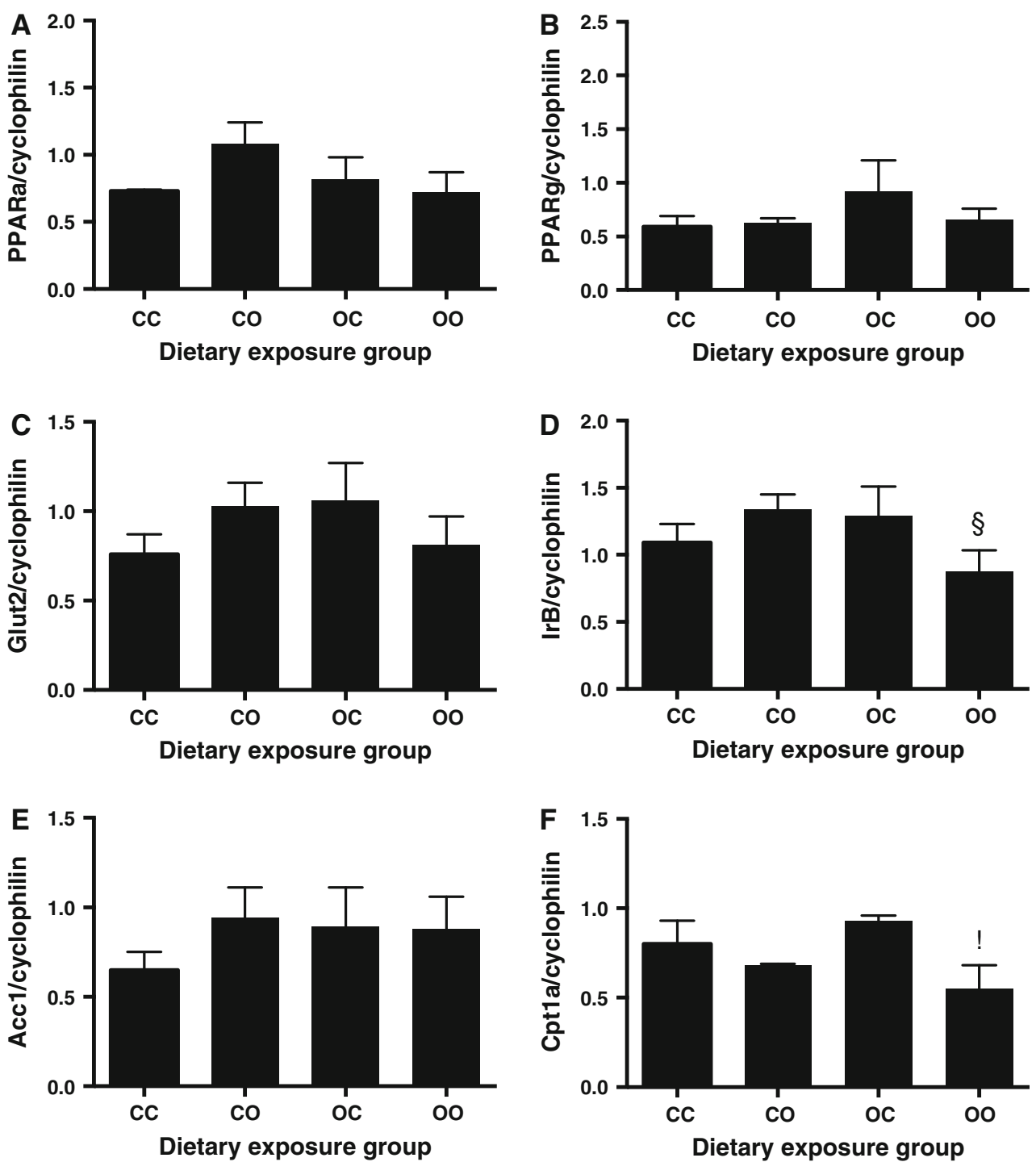

Table 2 DNA Methylation in liver of 3-month-old rats

\begin{tabular}{|c|c|c|c|c|c|c|c|c|}
\hline & \multicolumn{8}{|c|}{ Dietary exposure groups } \\
\hline & \multicolumn{2}{|l|}{$\mathrm{CC}$} & \multicolumn{2}{|l|}{$\mathrm{CO}$} & \multicolumn{2}{|l|}{$\mathrm{OC}$} & \multicolumn{2}{|l|}{$\mathrm{OO}$} \\
\hline & Male & Female & Male & Female & Male & Female & Male & Female \\
\hline 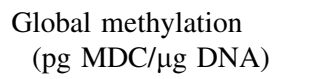 & $190 \pm 11$ & $174 \pm 12$ & $154 \pm 4$ & $176 \pm 4$ & $166 \pm 12$ & $160 \pm 6$ & $120 \pm 11$ & $212 \pm 5$ \\
\hline Methylation PPARg (\%) & $0.47 \pm 0.17$ & $0.42 \pm 0.20$ & $0.61 \pm 0.38$ & $0.48 \pm 0.23$ & $9.24 \pm 6.63$ & $9.19 \pm 6.62$ & $0.27 \pm 0.04$ & $0.21 \pm 0.04$ \\
\hline Methylation IrB (\%) & $0.60 \pm 0.14$ & $0.54 \pm 0.12$ & $1.43 \pm 0.68$ & $0.91 \pm 0.68$ & $13.1 \pm 7.72$ & $13.1 \pm 7.68$ & $0.46 \pm 0.05$ & $0.49 \pm 0.02$ \\
\hline
\end{tabular}

Data are shown as mean \pm SEM for 5-6 observations per group. Global methylation was influenced by the interaction of sex and post-weaning $\operatorname{diet}(P=0.018)$. Methylation of PPARg was not influenced by sex or diet at any stage. IrB methylation was significantly influenced by the interaction of diet in lactation and weaning $(P=0.036)$, with univariate influences of lactation $(P=0.058)$ and post-weaning $(P=0.054)$ diets approaching significance. MDC-5-methyl-2'-deoxy cytidine

and $A k t 1)$ are contributing to the metabolic response to the diet, and a role for Glut 2 has been excluded. As previously reported (Akyol et al. 2012), the differences in metabolic response to glucose are more likely to be due to this programming of the insulin signalling pathway or glucose metabolism as there were no gross effects of the cafeteria diet upon other aspects of metabolic function. Whilst the post-weaning cafeteria diet promoted fat deposition, there 
Fig. 4 Protein expression of insulin signalling pathwayrelated genes in rat liver at 3 months of age. Data are shown as mean \pm SEM for 4-5 observations per group. All protein expression was normalised to expression of beta-actin. Expression of all proteins, including the housekeeper beta-actin was not influenced by sex or dietary exposures. Blot examples shown are representative of each group. a Glut 2, b IRB, c PPARa, d PPARg
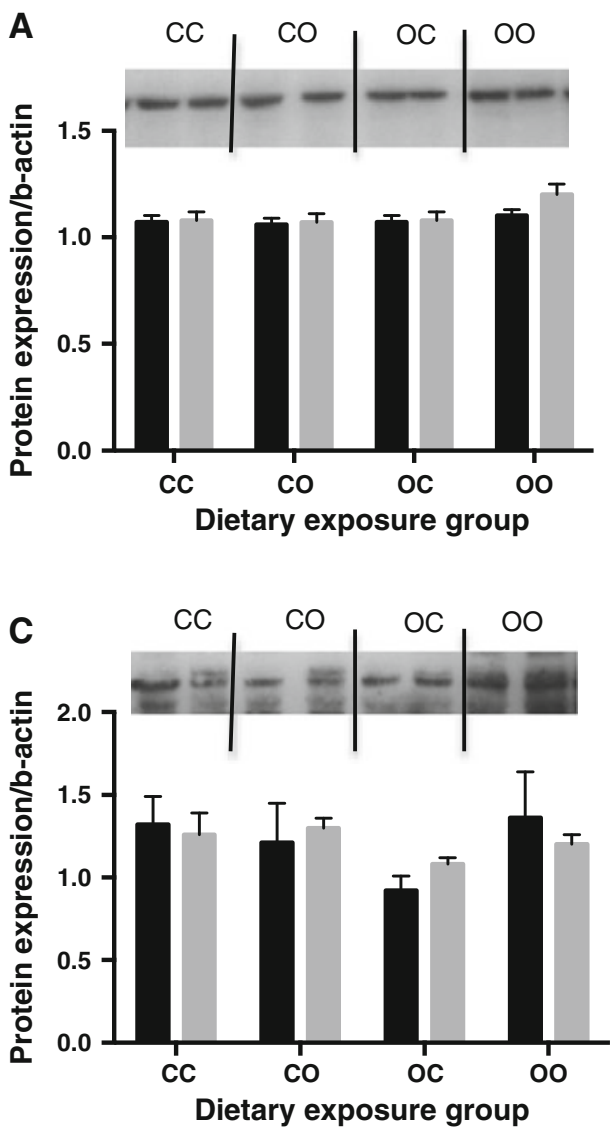

Female
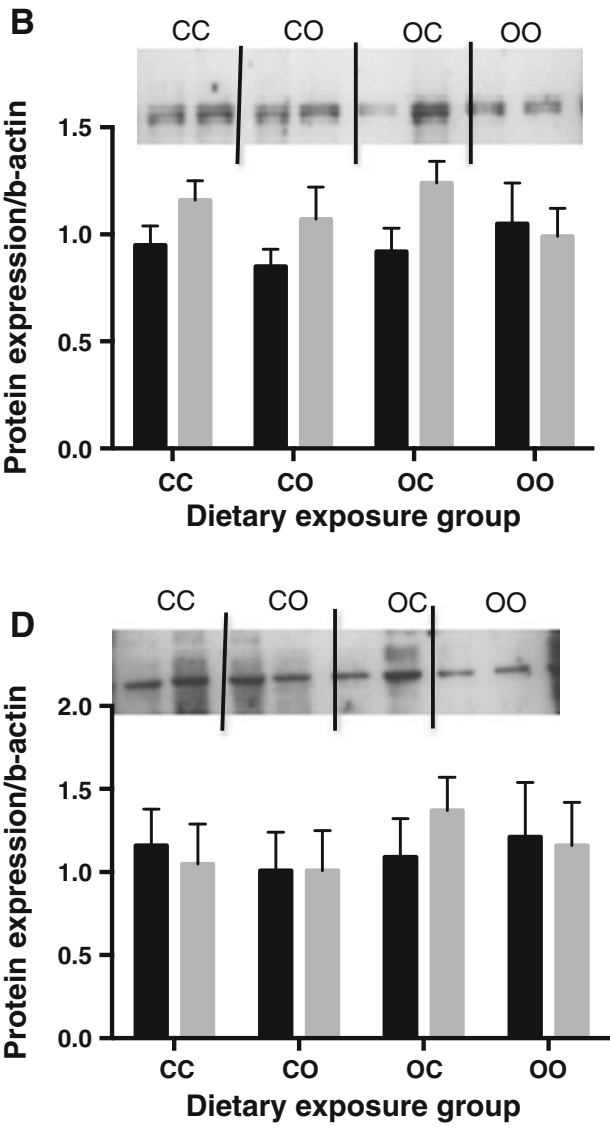

was no effect of the diet in lactation on body fatness. Abdominal fat deposition in $\mathrm{OC}$ rats was no different to $\mathrm{CC}$, and in $\mathrm{CO}$, there was no different to $\mathrm{OO}$ (Akyol et al. 2012). The data critically demonstrate that the transcriptional and metabolic effects seen in $\mathrm{OO}$ animals are not just a response to the diet at the time of measurement, as the nature of the response also depended upon the dietary exposure during lactation.

Using a similar protocol to the present study, Bayol et al. (2010) found sex-specific effects of cafeteria diet upon insulin signalling and glucose metabolism in rats. However, in the Bayol study, insulin receptor expression was increased by cafeteria feeding at any stage of life in males and $\operatorname{Irs} 2$ was down-regulated by cafeteria diet in females. Effects of the diet on expression of PPARg and glucose transporters in adipose tissue were also reported (Bayol et al. 2008). The differences between the current study and the work by Bayol and colleagues are most likely to be explained by variation in the nature of the cafeteria feeding regimens and different timing of exposure (control over litter size and variety of cafeteria foods offered).

The reanalysis of mRNA expression data in this study showed that Irs 2 was up-regulated in response to postweaning cafeteria feeding, and we would suggest that this is likely to be a compensatory response to maintain glucose homoeostasis. Aktl expression also responded to cafeteria feeding post-weaning, again an adaptation that would be expected to maintain homoeostasis in the face of increasing adiposity and dietary challenge. There was clear variation in response dependent upon the lactation exposure. Differential responses to the post-weaning dietary challenge between males and females were noted with respect to the nature of adaptive responses to over-feeding. Males upregulated PPARg rather than the Irs2/Akt pathway. This would provide a means of alternative disposal in glucose adipose tissue rather than liver. Sex differences in phenotypic outcomes of Irs2 (Masaki et al. 2004) and PPARg knockout (Duan et al. 2010; Kadowaki et al. 2007) and Akt1 activation (Foryst-Ludwig et al. 2011; Chen et al. 2013) have been reported previously.

The assessment of global DNA methylation did not note any effects of cafeteria diet during lactation. This may be unremarkable as simple assays of 5-methyl- $2^{\prime}$-deoxy cytidine are considerably less sensitive than sequencing based methods that were beyond the scope of this investigation. However, post-weaning diet did influence global methylation, consistent with reports of Vucetic et al. (2010). It is of interest that this effect was seen only in males. Sex 
differences in methylation are unexplained, but our observations are consistent with Sinclair et al. (2007) who similarly reported sensitivity of DNA methylation to maternal diet in males, but not females. As crude global methylation changes would be insufficient evidence that the diet impacted upon the genome, it is important to note that $\operatorname{Ir} B$ was the a specific gene target for which an effect of the diet upon DNA methylation was noted. However, whilst methylation was increased, there was no associated decrease in mRNA expression. In fact, quite the opposite was apparent. Discordance of DNA methylation and mRNA expression has been widely reported (Carone et al. 2010; Zhou et al. 2011). A recent, robust analysis of DNA methylation across the whole genome and genome-wide gene expression changes in response to maternal undernutrition found that discordance of methylation and gene expression was the norm (Altobelli et al. 2013). The discordance suggests that the interplay between DNA methylation and gene expression is complex. Differences in methylation may only, for example, bring about expression changes during a metabolic challenge or in response to a specific stimulus. Furthermore, the effect of methylation on expression of a specific gene will also depend upon the histone marks associated with that promoter. Liver is not a homogenous tissue and contains many distinct cell types. It is important to note that methylation and expression may differ between different cell types, and this may contribute to the discordance in the data.

A general lack of major effects of the diet during lactation upon methylation of DNA might also result from the window of epigenetic sensitivity being much wider that originally suspected. If the diet fed during weaning can also change epigenetic marks, and possibly in a different manner to earlier phases, then effects of diet in lactation could be masked or erased. Investigation of this would require a different experimental design with earlier timepoints to consider the epigenome during periods of transition from one diet to another. The study of Jacobsen et al. (2012) showed that when healthy young men were fed a short-term high-fat diet, there were changes in genomewide methylation in skeletal muscle, which reversed very slowly and were still present 8 weeks after the withdrawal of the diet. This is consistent with the view that dietary effects on the epigenome at one point in life can determine the response to nutritional cues and the impact of the diet upon the genome at another. With ageing, the nature of the epigenome will reflect an accumulation of methylation patterns that are generated by dietary and environmental exposures across the life course.

It is clear from the data presented in this paper that there was marked discordance between the mRNA and protein measurements, with none of the gene expression changes verified at the protein level. This is not entirely unsurprising as a number of studies have shown that at most only $40 \%$ of the protein levels in mammalian cells are related to mRNA expression even in homogenous tissues and cultures. (Vogel et al. 2010). Transcription factors, such as PPARa and PPARg, are among a large group of proteins where both mRNA and protein have high rates of turnover (Schwanhäusser et al. 2011). This applies also to cyclins which are apparent targets for nutritional programming in rats (Swali et al. 2011). The discordance of mRNA and protein data in this study could limit the capacity of the study to establish the underlying basis of physiological and metabolic phenotype, but does not lessen the significance of the observed effect of a highly variable, human-type, cafeteria diet upon transcription and the epigenome.

Feeding a cafeteria diet based upon highly palatable human foods to rats during lactation modulates the response of their offspring to the same dietary pattern postweaning. Programmed changes in hepatic gene expression underpin these differential responses and may be, in part, driven by differences in DNA methylation. The study adds to a growing evidence base that suggests tissue function across the lifespan is determined by cumulative modifications to the epigenome and hence transcriptome, which may be both tissue and sex-specific.

Acknowledgments This work was funded by a small project grant from Diabetes UK.

\section{Conflict of interest None.}

Ethical standard All institutional and national guidelines for the care and use of laboratory animals were followed.

\section{References}

Aagaard-Tillery KM, Grove K, Bishop J, Ke X, Fu Q, McKnight R, Lane RH (2008) Developmental origins of disease and determinants of chromatin structure: maternal diet modifies the primate fetal epigenome. J Mol Endocrinol 41:91-102

Akyol A, Langley-Evans SC, McMullen S (2009) Obesity induced by cafeteria feeding and pregnancy outcome in the rat. Br J Nutr 102:1601-1610

Akyol A, McMullen S, Langley-Evans SC (2012) Glucose intolerance associated with early-life exposure to maternal cafeteria feeding is dependent upon post-weaning diet. Br J Nutr 107:964-978

Altobelli G, Bogdarina I, Stupka E, Clark AJC, Langley-Evans SC (2013) Genome-wide methylation and gene expression changes in newborn rats following maternal protein restriction and reversal by folic acid. PLOS One (in press)

Austin RM, Langley-Evans SC (2011) Cultured neonatal rat cardiomyocytes display differences in glucose uptake and sensitivity to dexamethasone related to maternal diet. J DOHAD 2:190-194

Bayol SA, Simbi BH, Bertrand JA, Stickland NC (2008) Offspring from mothers fed a 'junk food' diet in pregnancy and lactation exhibit exacerbated adiposity that is more pronounced in females. J Physiol 586:3219-3230

Bayol SA, Simbi BH, Fowkes RC, Stickland NC (2010) A maternal "junk food" diet in pregnancy and lactation promotes 
nonalcoholic fatty liver disease in rat offspring. Endocrinology 151:1451-1461

Bogdarina I, Haase A, Langley-Evans SC, Clark AJ (2010) Glucocorticoid effects on the programming of AT1b angiotensin receptor gene methylation and expression in the rat. PLOS ONE 5(2): 9237

Buettner R, Scholmerich J, Bollheimer LC (2007) High-fat diets: modeling the metabolic disorders of human obesity in rodents. Obesity 15:798-808

Burdge GC, Lillycrop KA, Phillips ES, Slater-Jefferies JL, Jackson AA, Hanson MA (2009) Folic acid supplementation during the juvenile-pubertal period in rats modifies the phenotype and epigenotype induced by prenatal nutrition. J Nutr 139:10541060

Carlin J, George R, Reyes TM (2013) Methyl donor supplementation blocks the adverse effects of maternal high fat diet on offspring physiology. PLoS ONE 8:e63549

Carone BR, Fauquier L, Habib N, Shea JM, Hart CE et al (2010) Paternally induced transgenerational environmental reprogramming of metabolic gene expression in mammals. Cell 143: 1084-1096

Chen YW, Kao HY, Min MY, Lai WS (2013). A Sex- and RegionSpecific Role of Akt1 in the Modulation of MethamphetamineInduced Hyperlocomotion and Striatal Neuronal Activity: Implications in Schizophrenia and Methamphetamine-Induced Psychosis. Schizophr Bull (in press)

Crozier SR, Robinson SM, Borland SE, Inskip HM, SWS Study Group (2006) Dietary patterns in the Southampton Women's Survey. Eur J Clin Nutr 60:1391-1399

Duan SZ, Usher MG, Foley EL 4th, Milstone DS, Brosius FC 3rd, Mortensen RM (2010) Sex dimorphic actions of rosiglitazone in generalised peroxisome proliferator-activated receptor-gamma (PPAR-gamma)-deficient mice. Diabetologia 53:1493-1505

Fernandez-Twinn DS, Wayman A, Ekizoglou S, Martin MS, Hales CN, Ozanne SE (2005) Maternal protein restriction leads to hyperinsulinemia and reduced insulin-signaling protein expression in 21-mo-old female rat offspring. Am J Physiol Regul Integr Comp Physiol 288:R368-R373

Floyd ZE, Stephens JM (2012) Controlling a master switch of adipocyte development and insulin sensitivity: covalent modifications of PPAR $\gamma$. Biochim Biophys Acta 1822:1090-10955

Foryst-Ludwig A, Kreissl MC, Sprang C, Thalke B, Böhm C, Benz V, Gürgen D, Dragun D, Schubert C, Mai K, Stawowy P, Spranger J, Regitz-Zagrosek V, Unger T, Kintscher U (2011) Sex differences in physiological cardiac hypertrophy are associated with exercise-mediated changes in energy substrate availability. Am J Physiol Heart Circ Physiol 301:H115-H122

Gambling L, Dunford S, Wallace DI, Zuur G, Solanky N, Srai SK, McArdle HJ (2003) Iron deficiency during pregnancy affects postnatal blood pressure in the rat. J Physiol 552:603-610

Jacobsen SC, Brøns C, Bork-Jensen J, Ribel-Madsen R, Yang B, Lara E, Hall E, Calvanese V, Nilsson E, Jørgensen SW, Mandrup S, Ling C, Fernandez AF, Fraga MF, Poulsen P, Vaag A (2012) Effects of short-term high-fat overfeeding on genome-wide DNA methylation in the skeletal muscle of healthy young men. Diabetologia 55:3341-3349

Kadowaki K, Fukino K, Negishi E, Ueno K (2007) Sex differences in PPARgamma expressions in rat adipose tissues. Biol Pharm Bull 30:818-820

Kahn A (1997) Transcriptional regulation by glucose in the liver. Biochimie 79:113-118

Kant AK (2004) Dietary patterns and health outcomes. J Am Diet Assoc 104:615-635

Langie SA, Achterfeldt S, Gorniak JP, Halley-Hogg KJ, Oxley D, van Schooten FJ, Godschalk RW, McKay JA, Mathers JC (2013) Maternal folate depletion and high-fat feeding from weaning affects DNA methylation and DNA repair in brain of adult offspring. FASEB J27:3323-3334

Langley SC, Jackson AA (1994) Increased systolic blood pressure in adult rats induced by fetal exposure to maternal low protein diets. Clin Sci 86:217-222

Langley-Evans SC, Welham SJ, Jackson AA (1999) Fetal exposure to a maternal low protein diet impairs nephrogenesis and promotes hypertension in the rat. Life Sci 64:965-974

Lillycrop KA, Burdge GC (2011) Epigenetic changes in early life and future risk of obesity. Int J Obes 35:72-83

Lillycrop KA, Slater-Jefferies JL, Hanson MA, Godfrey KM, Jackson AA, Burdge GC (2007) Induction of altered epigenetic regulation of the hepatic glucocorticoid receptor in the offspring of rats fed a protein-restricted diet during pregnancy suggests that reduced DNA methyltransferase-1 expression is involved in impaired DNA methylation and changes in histone modifications. Br J Nutr 97:1064-1073

Lowry OH, Rosebrough NJ, Farr AL, Randall RJ (1951) Protein measurement with the Folin phenol reagent. J Biol Chem 193:265-275

Masaki T, Chiba S, Noguchi H, Yasuda T, Tobe K, Suzuki R, Kadowaki T, Yoshimatsu H (2004) Obesity in insulin receptor substrate-2-deficient mice: disrupted control of arcuate nucleus neuropeptides. Obes Res 12:878-885

McMullen S, Langley-Evans SC (2010) The developmental origins of adult disease. Med Princ Pract 19:87-98

Menendez-Gutierrez MP, Roszer T, Ricote M (2012) Biology and therapeutic applications of peroxisome proliferator-activated receptors. Curr Top Med Chem 12:548-584

Rothwell NJ, Stock MJ (1979) Regulation of energy balance in two models of reversible obesity in the rat. J Comp Physiol Psychol 93:1024-1034

Ryan KJP, Elmes MJ, Gardner DS, Langley-Evans SC (2012) The effects of prenatal protein restriction on B-adrenergic signalling of the adult rat heart during ischaemia. J Nutr Metab 12:397389

Sampey BP, Vanhoose AM, Winfield HM, Freemerman AJ, Muehlbauer MJ, Fueger PT, Newgard CB, Makowski L (2011) Cafeteria diet is a robust model of human metabolic syndrome with liver and adipose inflammation: comparison to high-fat diet. Obesity 19:1109-1117

Samuelsson AM, Matthews PA, Argenton M, Christie MR, McConnell JM, Jansen EH, Piersma AH, Ozanne SE, Twinn DF, Remacle C, Rowlerson A, Poston L, Taylor PD (2008) Diet-induced obesity in female mice leads to offspring hyperphagia, adiposity, hypertension, and insulin resistance: a novel murine model of developmental programming. Hypertension 51:383-392

Schwanhäusser B, Busse D, Li N, Dittmar G, Schuchhardt J, Wolf J, Chen W, Selbach M (2011) Global quantification of mammalian gene expression control. Nature 473:337-342

Seki Y, Williams L, Vuguin PM, Charron MJ (2012) Minireview: epigenetic programming of diabetes and obesity: animal models. Endocrinology 153:1031-1038

Shankar K, Harrell A, Liu X, Gilchrist JM, Ronis MJ, Badger TM (2008) Maternal obesity at conception programs obesity in the offspring. Am J Physiol Regul Integr Comp Physiol 294:R528R538

Sinclair KD, Allegrucci C, Singh R, Gardner DS, Sebastian S, Bispham J, Thurston A, Huntley JF, Rees WD, Maloney CA, Lea RG, Craigon J, McEvoy TG, Young LE (2007) DNA methylation, insulin resistance, and blood pressure in offspring determined by maternal periconceptional B vitamin and methionine status. Proc Natl Acad Sci USA 104:19351-19356

Swali A, McMullen S, Hayes H, Gambling L, McArdle H, LangleyEvans SC (2011) Cell cycle regulation and cytoskeletal remodelling are critical processes in the nutritional programming of embryonic development. PLoS ONE 6:e23189 
Swali A, McMullen S, Hayes H, Gambling L, McArdle HJ, LangleyEvans SC (2012) Processes underlying the nutritional programming of embryonic development by iron deficiency in the rat. PLoS ONE 7:e48133

Szyf M (2009) The early life environment and the epigenome. Biochim Biophys Acta 1790:878-885

Torrens C, Hanson MA, Gluckman PD, Vickers MH (2009) Maternal undernutrition leads to endothelial dysfunction in adult male rat offspring independent of postnatal diet. Br J Nutr 101:27-33

Viana Abranches M, Esteves de Oliveira FC, Bressan J (2011) Peroxisome proliferator-activated receptor: effects on nutritional homeostasis, obesity and diabetes mellitus. Nutr Hosp 26:271-279

Vickers MH, Breier BH, McCarthy D, Gluckman PD (2003) Sedentary behavior during postnatal life is determined by the prenatal environment and exacerbated by postnatal hypercaloric nutrition. Am J Physiol Regul Integr Comp Physiol 285:R271R273

Vogel C, Abreu Rde S, Ko D, Le SY, Shapiro BA, Burns SC, Sandhu D, Boutz DR, Marcotte EM, Penalva LO (2010) Sequence signatures and mRNA concentration can explain two-thirds of protein abundance variation in a human cell line. Mol Syst Biol 6:400
Vucetic Z, Kimmel J, Totoki K, Hollenbeck E, Reyes TM (2010) Maternal high-fat diet alters methylation and gene expression of dopamine and opioid-related genes. Endocrinology 151:4756-4764

Vucetic Z, Kimmel J, Reyes TM (2011) Chronic high-fat diet drives postnatal epigenetic regulation of $\mu$-opioid receptor in the brain. Neuropsychopharmacology 36:1199-1206

Wright T, Langley-Evans SC, Voigt JP (2011a) The impact of maternal cafeteria diet on anxiety-related behaviour and exploration in the offspring. Physiology and Behaviour 103:164-172

Wright T, Fone K, Langley-Evans SC, Voigt JP (2011b) Exposure to maternal consumption of cafeteria diet during the lactation period programmes feeding behaviour in the rat. Int J Develop Neurosci 29:785-793

Yates Z, Tarling EJ, Langley-Evans SC, Salter AM (2008) Maternal undernutrition programmes atherosclerosis in the Apo $E^{*} 3$ Leiden mouse. Br J Nutr 101:1185-1194

Zhou Z, Yuan Q, Mash DC, Goldman D (2011) Substance-specific and shared transcription and epigenetic changes in the human hippocampus chronically exposed to cocaine and alcohol. Proc Natl Acad Sci USA 108:6626-6631 